Tohoku J. Exp. Med., 2005, 207, 125-132

\title{
High Body Mass Index and Long Duration of Intubation Increase Post-Extubation Stridor in Patients with Mechanical Ventilation
}

\author{
Sinan Erginel, Irfan Ucgun, Huseyin Yildirim, Muzaffer Metintas and \\ SEBNEM PARSPOUR \\ Osmangazi University, Medical Faculty, Department of Chest Diseases, \\ Respiratory Intensive Care Unit, Eskisehir, Turkey
}

\begin{abstract}
Erginel, S., Ucgun, I., Yildirim, H., Metintas, M. and Parspour, S. High Body Mass Index and Long Duration of Intubation Increase Post-Extubation Stridor in Patients with Mechanical Ventilation. Tohoku J. Exp. Med., 2005, 207 (2), 125-132 — Approximately $20 \%$ of mechanically ventilated patients experience post-extubation stridor (PES) and reintubation, which subsequently may lead to an increased risk of morbidity and mortality. The risk of PES development is significantly higher in obese patients. Low air leakage between the endotracheal tube and the trachea, following cuff deflation, may indicate a higher risk for the development of PES. The aim of this study is to identify the relationship between body mass index (BMI) and PES using the cuff-leak test in patients intubated in the respiratory intensive care unit. A total of 67 consecutive intubations on 56 different ventilated patients were included in this study. The mean age was $63.6 \pm 12.1$ years and $84 \%$ of the patients were male. PES developed in seven patients $(10.4 \%)$. The mean cuffleak volume was $395 \pm 187 \mathrm{ml}$ in non-PES patients and $240 \pm 93 \mathrm{ml}$ in PES patients $(p=$ $0.023)$. The mean BMI was $36 \pm 13 \mathrm{~kg} / \mathrm{m}^{2}$ in PES patients and $24 \pm 7 \mathrm{~kg} / \mathrm{m}^{2}$ in non-PES patients $(p=0.046)$. BMI $>26.5 \mathrm{~kg} / \mathrm{m}^{2}$ (OR: 1.2$)$, low cuff-leak volume $(<283 \mathrm{ml})$ and mechanical ventilation required for more than 5 days (OR: 0.9) were independent variables for PES occurrence. We therefore suggest that non-obese patients, short-term intubated patients and those having a high air leakage around the endotracheal tube could be extubated without much difficulty. —_ intensive care unit; cuff-leak test; body mass index; post-extubation stridor; reintubation
\end{abstract}

(C) 2005 Tohoku University Medical Press

Intubation can lead to laryngotracheal trauma and, therefore, may necessitate reintubation in $20 \%$ of mechanically ventilated patients. Postextubation problems, including stridor, cause a significant mortality and morbidity risk in pa- tients, especially when reintubation is required (Miller and Cole 1996; Sandhu et al. 2000; MacIntyre et al. 2001). In patients with obesity, the risk of post-extubation stridor (PES) is common due to swelling of the upper airways, which

Received June 10, 2005; revision accepted for publication July 22, 2005.

Correspondence: Irfan Ucgun, Osmangazi University, Medical Faculty, Department of Chest Diseases, 26040

Meselik, Eskisehir, Turkey.

e-mail: irfanucgun@hotmail.com

A part of this study was presented at the European Respiratory Society 15th Annual Congress, Glasgow, Scotland, 2004. 
predisposes to a lower functional residual capacity which can contribute to atelectasis and subsequent hypoxemia during the transition to unassisted breathing (Manthous et al. 1998; El-Solh et al. 2001). In addition to obesity, elongated intubation may also increase the frequency of PES and reintubation.

After an unsuccessful extubation, the need for reintubation leads to a significant increase in mortality and morbidity (Miller and Cole 1996; Epstein and Ciubotaru 1998; Sandhu et al. 2000). The main reason for reintubation is due to the rise in the extent of tracheal edema, which leads to an increase in breathing. However, the predictors of successful extubation remain empirical in the majority of patients. It has previously been shown that air leakage from the endotracheal tube can be a useful marker to indicate the absence of laryngotracheal swelling and successful extubation (Miller and Cole 1996). The expiratory tidal volume passing through the mechanical ventilator can be measured when the cuff of the endotracheal tube is inflated. However, once the cuff has been deflated, a considerable amount of the expiratory tidal volume leaks between the endotracheal tube and the trachea. Therefore, the volume measured is remarkably low. The difference measured between the tidal volumes pre- and post-deflation of the cuff is referred to as "cuff leakage." It is believed that the lower the leakage around the tube, the larger the extent of laryngotracheal edema.

In theory, no objective criteria in determining successful extubation are available and no other test is available, except the cuff-leak test (CLT), to identify PES and the risk of reintubation (Raskin and Davis 1986; Demling et al. 1988; Krieger et al. 1989; Brochard et al. 1994; Torres et al. 1995). PES and post-intubation problems are observed more often in patients with obesity. Therefore, the aim of this study was to demonstrate the efficacy of the cuff-leak test in predicting PES in patients with a high body mass index (BMI) and patients undergoing a longer duration of mechanical ventilation.

\section{Materials ANd Methods}

This study was carried out with 67 consecutive intubations on 56 different mechanically ventilated adult patients, suffering from a variety of respiratory diseases, in the respiratory intensive care unit (RICU), between November 2003 and 2004. Eleven of the patients required intubation twice in one year. Patients intubated for less than 24 hours, patients deemed unsuitable for extubation due to chronic irreversible respiratory failure (RF), as neuromuscular diseases, and patients who extubated themselves before they could undergo the cuff-leak test were excluded from this study. The patients in this study had acute exacerbation of chronic obstructive pulmonary disease (COPD), restrictive lung diseases and/or hypoxemic respiratory failures, such as pulmonary edema, severe pneumonia and acute respiratory distress syndrome (ARDS). This prospective study was conducted in the University Hospital and the Ethical Practices Committee of Osmangazi University approved the study.

Decisions for intubation, extubation, weaning and reintubation were made, based on standard criteria. Criteria for intubation (Pierson 2004): 1) apnea or respiratory pauses with loss of consciousness, gasping for air or imminent respiratory arrest; 2) severe tachypnea or severe dyspnea, and at least one of the following; (a) persistent uncooperativeness; (b) acute cardiovascular instability; (c) inability to protect the lower airway; (d) intolerance to non-invasive mechanical ventilation (NIV). Criteria for weaning (MacIntyre et al. 2001): 1) a favorable clinical response or improvement of the underlying cause of acute RF; 2) an ability to communicate, with a Glasgow Coma Score (GCS) above 10 (following discontinuation of sedation); 3) a core temperature $<38^{\circ} \mathrm{C}$; 4) hemodynamic stability and non usage of vasoactive agents, except for low doses of renal dopamine $(<5$ $\mu \mathrm{g} / \mathrm{kg} / \mathrm{min}$ ); and 5) adequate gas exchange indicated by a $\mathrm{PaO}_{2}>60 \mathrm{mmHg}$ while breathing with an $\mathrm{FiO}_{2}$ of $40 \%$ or less with a positive end-expiratory pressure (PEEP) of $5 \mathrm{cmH}_{2} \mathrm{O}$ or less. Criteria for extubation: 1) the success of spontaneous ventilation up to $120 \mathrm{~min}$ using a T-tube; and 2) the ability to cough and expectorate.

CLT: The expiratory tidal volume passing through the mechanical ventilator was measured following cuff inflation of the endotracheal tube. Following cuff deflation, a considerable amount of the expiratory tidal volume was found to have leaked between the endotracheal tube and the trachea, the volume measured being notably low. The difference between the tidal volumes measured 
both pre- and post-cuff deflation was referred to as "cuff leakage." The CLT was performed, during the 2 hour period prior to extubation, according to the original report by Fisher and Raper (1992) and the method described by Miller and Cole (1996), in order to assess any air leakage between the endotracheal tube and the trachea. Prior to the test, the patient was placed on the assist control mode with a tidal volume $\left(\mathrm{V}_{\mathrm{T}}\right)$ of $7 \mathrm{ml} / \mathrm{kg}$. The endotracheal, oral and supraglottic secretions were then suctioned. The operator-selected inspiratory $\mathrm{V}_{\mathrm{T}}$ and the first six expiratory $\mathrm{V}_{\mathrm{T}}$ values displayed were recorded. Subsequently, the balloon cuff was deflated and balloon volume measured, with the expiratory tidal volume recorded over six subsequent respiratory cycles. The difference between the averages for the six expiratory $V_{T}$ values and the minimum three expiratory tidal volumes of the first six $V_{T}$ values following deflation of the cuff was defined as the "cuff-leak volume." The "percentage of the cuff-leak volume" was calculated by dividing the mean cuff-leak volume by the mean expiratory tidal volume (the average of the lowest three expiratory tidal volumes of the first $6 \mathrm{~V}_{\mathrm{T}}$ ). Once the CLT was completed, sedation was discontinued and the patients were placed on T-tube ventilation for 2 hours. Weaning from mechanical ventilation began once the patients achieved the capability of initiating a spontaneous breath. Providing the extubation criteria were met, the endotracheal tube was then removed. The data obtained from the CLT were not used as criteria for extubation. Post-extubation stridor was defined as the presence of a high-pitched inspiratory wheeze localized to the trachea or larynx.

Number 7.0-8.5 endotracheal tubes (Portex tracheal tube, soft seal cuff, Hythe, UK) were used for intubation of patients. Age, gender, BMI, cause of RF, duration of mechanical ventilation (MV), medications, endotracheal tube size, tube cuff volume, CLT, PES and reintubation parameters were recorded for all patients included in this study. Steroids were not routinely used prior to extubation, however, parameters were recorded for patients using steroids for other reasons such as anti-edema, bronchodilation and stress dose in sepsis.

The APACHE II score was determined using the most unfavorable values available during the first 24 hours in ICU, as previously described in the literature (Knaus et al. 1985). The Glasgow Coma Score (GCS) was used to estimate the level of consciousness in all patients (Teasdale and Jennett 1974).
Statistical analysis

Variables were assessed for each patient using the chi-squared test for categorical variables and an unpaired Student's $t$-test or a Mann-Whitney's U-test for continuous variables. A multiple logistic regression analysis model, with backward stepwise analysis was used in order to determine PES-related factors in intubated patients. Comparisons of clinical and laboratory variables with a $p$ value lower than 0.05 , determined using univariate analysis, were assessed in the model. A receiver operating characteristic (ROC) curve for assessment of the predictive value of PES, using the CLT, was constructed by plotting the sensitivities for all individual CLT cut-off values against the corresponding 1-specificity value (Zweig and Campbell 1993). The cuff-leak threshold volume was calculated following an analysis of the ROC. In order to determine a global measurement of the parameter's discrimination, the area under the ROC curve was calculated. The data was processed using SPSS for Windows 12 (SPSS, Chicago, IL, USA). A $p$ value $<0.05$ was considered to be of statistical significance.

\section{Results}

A total of 67 consecutive intubations on 56 different mechanically ventilated adult patients, were studied. The mean age was 63.6 years and 56 of the patients $(83.6 \%)$ were male. The general features of all patients have been summarized in Table 1.

Post-extubation stridor developed in seven patients $(10.4 \%)$, who subsequently required reintubation, four of whom were females $(57 \%)$. The frequency of PES was $36.4 \%$ in women and $5.4 \%$ in men $(p=0.011)$. Sex, cuff-leak volume, percentage of the cuff-leak volume, need for MV for more than 5 days, APACHE II score and BMI were significantly different between the two groups.

The mean cuff-leak volume was $395 \mathrm{ml}$ in non-PES patients and $240 \mathrm{ml}$ in PES patients $(p=$ 0.023 ). The cuff-leak threshold volume was 283 $\mathrm{ml}$. We calculated the percentage of the cuff-leak volume (the average of the lowest three expiratory tidal volumes of the first $6 \mathrm{~V}_{\mathrm{T}}$ ) by dividing the mean cuff-leak volume by the mean expiratory tidal volume. This ratio was $50.9 \%$ in the PES patients, while it was $72.6 \%$ in those who did not develop PES $(p=0.00057)$. 
TABLE 1. Univariate analysis of the patients with and without post-extubation stridor

\begin{tabular}{lcccc}
\hline & All intubations & \multicolumn{2}{c}{ Post-extubation stridor } & \\
\cline { 3 - 4 } Feature & $(n=67)^{\dagger}$ & $\begin{array}{c}\text { Absent } \\
(n=60)\end{array}$ & $\begin{array}{c}\text { Present } \\
(n=7)\end{array}$ & $p$ value \\
\hline Age (years) & $63.6 \pm 12.1$ & $63.1 \pm 12.4$ & $68.3 \pm 8.8$ & 0.19 \\
Cause of RF $(n)$ & & & & \\
$\quad$ Acute exacerbation of COPD & 53 & 49 & 4 & 0.10 \\
Restrictive pulmonary diseases & 3 & 2 & 1 & - \\
Acute hypoxemic RF & 11 & 9 & 2 & - \\
Gender (M/F) & $56 / 11$ & $53 / 7$ & $3 / 4$ & $0.01^{*}$ \\
Tube size (mm) & $7.9 \pm 0.3$ & $7.9 \pm 0.3$ & $8.0 \pm 0.4$ & 0.76 \\
Cuff volume (ml) & $9.6 \pm 0.7$ & $9.4 \pm 0.8$ & $9.6 \pm 0.7$ & 0.60 \\
Steroid use $\mathrm{n}(\%)$ & $2(3.0 \%)$ & $1(1.7 \%)$ & $1(14.3 \%)$ & 0.20 \\
Mean duration of MV (days) & $5.6 \pm 4.6$ & $5.3 \pm 4.6$ & $8.0 \pm 4.6$ & 0.15 \\
Duration of MV $>5$ days $\mathrm{n}(\%)$ & $21(31.3 \%)$ & $16(26.7 \%)$ & $5(71.4 \%)$ & $0.027^{*}$ \\
Cuff-leak volume (ml) & $379 \pm 185$ & $395 \pm 187$ & $240 \pm 93$ & $0.023^{*}$ \\
Cuff-leak volume $(\%)$ & $70.4 \%$ & $72.6 \%$ & $50.9 \%$ & $0.00057^{*}$ \\
BMI (kg/m $\left.{ }^{2}\right)$ & $25.4 \pm 8.7$ & $24.1 \pm 7.3$ & $36.1 \pm 12.6$ & $0.046^{*}$ \\
APACHE II score & $19.7 \pm 4.2$ & $19.3 \pm 4.1$ & $23.4 \pm 4.2$ & $0.013^{*}$ \\
\hline
\end{tabular}

$\mathrm{RF}$, respiratory failure; $\mathrm{M}$, male; F, female; COPD, chronic obstructive pulmonary disease; APACHE II, acute physiology and chronic health evaluation II; MV, mechanical ventilation; BMI, body mass index.

${ }^{\dagger}$ Eleven of the patients required intubation twice in one year.

* Statistically significant. All features except causes of RF are given as mean \pm S.D.

The percentage of the cuff-leak volume was obtained by dividing the mean cuff-leak volume by the mean expiratory tidal volume.

The mean BMI was $36.1 \mathrm{~kg} / \mathrm{m}^{2}$ in patients who developed PES, but $24.1 \mathrm{~kg} / \mathrm{m}^{2}$ in non-PES patients $(p=0.046)$. The need for MV, for more than 5 days, in the reintubated group was higher than that of the non-PES group (71.4\% vs $26.7 \%$, respectively; $p=0.027$ ).
The sensitivity, specificity, positive predictive value (PPV), negative predictive value (NPV) and the area under the ROC curve of cuff-leak volume, cuff-leak percent, BMI and MV days are presented in Table 2.

Multiple logistic regression analysis was

TABLE 2. The sensitivity, specificity, PPV, NPV and area under the ROC curve for parameters with a significant effect on post-extubation stridor development

\begin{tabular}{lccccc}
\hline & Sensitivity & Specificity & PPV & NPV & ROC \\
\hline Cuff-leak volume $<283(\mathrm{ml})$ & 85.7 & 76.7 & 30 & 97.9 & 0.785 \\
Cuff-leak percent $<57 \%$ & 85.7 & 76.7 & 30 & 97.9 & 0.821 \\
BMI $>26.5\left(\mathrm{~kg} / \mathrm{m}^{2}\right)$ & 85.7 & 85 & 40 & 98.1 & 0.850 \\
Duration of $\mathrm{MV}>5$ days & 71.4 & 73.3 & 23.8 & 95.7 & 0.699 \\
\hline
\end{tabular}

PPV, positive predictive value; NPV, negative predictive value; ROC, area under the ROC curve. The percentage of the cuff-leak volume was obtained by dividing the mean cuff-leak volume by the mean expiratory tidal volume. 
TABLE 3. Multiple logistic regression analysis of parameters affecting post-extubation stridor

\begin{tabular}{lccl}
\hline & $p$ value & OR & \multicolumn{1}{c}{$95 \%$ CI } \\
\hline BMI $>26.5\left(\mathrm{~kg} / \mathrm{m}^{2}\right)$ & 0.008 & 1.20 & $1.05-1.38$ \\
Duration of $\mathrm{MV}>5$ days & 0.014 & 70.40 & $2.36-2,098.03$ \\
Cuff-leak volume $<57.2 \%$ & 0.026 & 0.92 & $0.86-0.99$
\end{tabular}

OR, odds ratio; CI, confidence interval; BMI, body mass index; MV, mechanical ventilation.

The percentage of the cuff-leak volume was obtained by dividing the mean cuff-leak volume by the mean expiratory tidal volume.

used to identify the independent risk factors for PES. Six variables with values of $p<0.05$ on univariate analysis were included in the regression analysis (sex, BMI, cuff-leak volume, percentage of cuff-leak volume, APACHE II score and MV for more than 5 days). As a result, BMI, percentage of cuff-leak volume, and the need for MV for more than 5 days were found to be independent parameters for PES development (Table $3)$.

PES occurred in four patients who had three risk factors (BMI, percentage of cuff-leak volume, and need for MV for more than 5 days). However, in 30 patients without any risk factors present, PES did not occur (Fig. 1).

\section{Discussion}

In the present study, the frequency of PES and reintubation in patients requiring mechanical ventilation (MV) for more than 24 hours was $10.4 \%$. In other studies, the frequency of PES was reported to vary between $0.57 \%$ and $17.8 \%$ (Tobin and Alex 1994; Ho et al. 1996; Marik 1996; Miller and Cole 1996; Efferen and Elsakr 1998; Engoren 1999; Sandhu et al. 2000; De Bast et al. 2002; Jaber et al. 2003; Maury et al. 2004). In relation to the present study, less experienced residents and less ideal conditions for intubation in our ICU may have led to greater airway trauma, and thus, to a higher incidence of PES. It is known that a long intubation time (Sandhu et al. 2000), female sex (Ho et al. 1996; Epstein and Ciubotaru 1998) and obesity (MacIntyre et al. 2001) increase the frequency of PES. Esteban et al. (1999), found that the mortality rate for reintu-

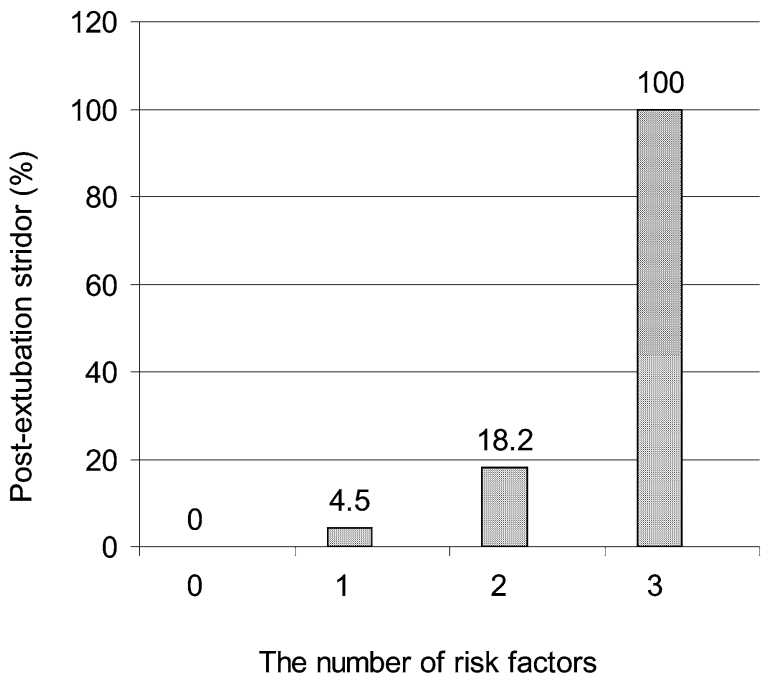

Fig. 1. The frequency of PES according to the number of risk factors.

(Body mass index, percentage of the cuff-leak volume and the need for mechanical ventilation for more than 5 days). No risk factor in 30 patients, one risk factor in 22 patients, two risk factors in 11 patients, and three risk factors in 4 patients. Eleven of the patients required intubation twice in one year.

bated patients was $32.8 \%$ and that this result was markedly higher then in patients who tolerated extubation (4.6\%).

The CLT is the only test available that can be used to determine the need for reintubation. Fisher and Raper (1992) initially used the CLT in 1992 and reported that it was useful in determining complications such as PES. The application method and the threshold value were determined by Miller and Cole (1996). However, although 
this method has been used and its effectiveness has been tested in many studies, the low predictive value and some contradictory results between studies have restricted its widespread use. In previous studies, PES development was determined and results including sensitivity of $0-80 \%$, specificity of $72-99 \%$, PPV of $0-95 \%$ and NPV of 96-99\% have been reported (Miller and Cole 1996; Engoren 1999; Sandhu et al. 2000; De Bast et al. 2002; Jaber et al. 2003). These studies have shown that CLT is not an effective indicator of PES development but can be used for prediction of patients who are not at risk of developing PES (Manthous et al. 1998; Engoren 1999; De Bast et al. 2002). Several studies have shown that this method was effective in the determination of PES (Miller and Cole 1996; De Bast et al. 2002; Maury et al. 2004), whereas, other studies have demonstrated its ineffectiveness (Engoren 1999). In fact, Engoren (1999) reported that widespread use of this method was not recommended. In his study, the results were not expressive, and sensitivity and PPV were found to be $0 \%$. We believe the reason for such results, was due to the fact, that this method was used after a mean of 12.9 hours intubation during the perioperative period. In the present study, we determined the CLT efficacy in patients who had MV for a mean duration of 5.6 days.

Although the CLT threshold value was determined to be $110 \mathrm{ml}$ by Miller and Cole (1996) in their original study, we determined a value of 283 $\mathrm{ml}$ in the present study. We calculated a cuff-leak volume of $395 \mathrm{ml}$ in non-PES patients and $240 \mathrm{ml}$ in those who developed PES $(p=0.035)$. In a previous study by Jaber et al. (2003), the threshold value determined was $130 \mathrm{ml}$ for the same test in 2003. In the present study, if we had accepted the threshold value as $110 \mathrm{ml}$, as in the study by Miller and Cole (1996), the sensitivity would have been $0 \%$ and the specificity $91.7 \%$.

Some studies have reported that it would be more appropriate to use the leakage as a percentage (the ratio of leak volume to mean expiratory $\mathrm{V}_{\mathrm{T}}$ ) rather than the volume in ml (Sandhu et al. 2000; De Bast et al. 2002; Jaber et al. 2003). For example, De Bast et al. (2002) reported that the threshold value for the leak around an endotracheal tube was $15.5 \%$, whereas, it was reported as $12 \%$ by Jaber et al. (2003). We reported a value of $57 \%$. We attributed such a high value to the use of the lowest three of six $V_{T}$ values, following deflation of the endotracheal tube cuff, in the cuffleak test.

It was observed, that requirement for MV for more than 5 days, cuff-leak volume, the percentage cuff-leak volume, female gender, APACHE II score, and BMI had a significant effect on PES development. Using multiple logistic regression analysis, the effect of three of these parameters was found to be independent of the others (BMI, percentage cuff-leak volume, and MV for more than 5 days). It has been reported in previous studies, that long-term MV (especially for more than 3 days) increases the frequency of PES development (Sandhu et al. 2000). In the present study, the requirement for MV, for a period longer than 5 days, was higher in patients who developed PES (71.4\% vs $26.7 \%)$.

Ho et al. (1996) reported that there was a higher incidence of PES development in women (39\% vs $17 \%$ ). We observed a similar finding (36.4\% vs $5.4 \%)$. Our results suggest that a high BMI (23 vs $37 \mathrm{~kg} / \mathrm{m}^{2}$ ), long-term MV (5.3 vs 6.8 days), and less leakage in the CLT (413 vs 203 $\mathrm{ml}$ ) may account for the higher frequency of PES development in female patients.

In the present study, a higher BMI significantly increased the frequency of PES development. Although it has been reported that intubation presents a greater difficulty in patients with a high BMI (Voyagis et al. 1998; Mansharamani et al. 2000; MacIntyre et al. 2001; Wong et al. 2004), respiratory complications (Asai et al. 1998) and obstructive sleep apnea (Tun et al. 2003) are observed more frequently, and the mortality rate is higher (Tremblay and Bandi 2003). To the best of our knowledge, the relationship between BMI and the CLT has not been pointed out in previous studies. In other studies, it has been reported that a higher BMI (27-30 kg/m²) could lead to difficult intubation and PES development (Voyagis et al. 1998; Mansharamani et al. 2000; MacIntyre et al. 2001; Wong et al. 2004). 
The limitations of the present study were a relatively low number of patients, a low number of female patients and the failure to measure the pressure of the endotracheal tube cuff.

It has been previously reported that a low cuff-leak volume does not necessarily result in PES, but what is certain, is that a high cuff-leak volume rarely results in PES. MV patients with a CLT result of lower than $283 \mathrm{ml}$ (or $<57 \%$ leak), who require $\mathrm{MV}$ for more than 5 days and have a BMI $>26.5 \mathrm{~kg} / \mathrm{m}^{2}$, have a higher risk of developing PES.

The frequency of PES observed in patients who had all three risk factors was $100 \%$. For this reason, we suggest that physicians be vigilant to reintubation in patients with obesity, who are intubated for more than 5 days, and who have a low cuff-leak volume. Our study suggests that the CLT could be useful in determining the likelihood of PES before extubation in obese and long-term ventilated patients. We would also suggest that non-obese patients, short-term intubated patients and those having a high air leakage around the endotracheal tube could be extubated without much difficulty.

\section{Acknowledgements}

The authors are indebted to Cengiz Bal (Osmangazi University, Medical Faculty, Department of Biostatistics) for help with the statistical analyses.

\section{References}

Asai, T., Koga, K. \& Vaughan, R.S. (1998) Respiratory complications associated tracheal intubation on extubation. Br. J. Anaesth., 80, 767-775.

Brochard, L., Rauss, A., Benito, S., Conti, G., Mancebo, J., Rekik, N., Gasparetto, A. \& Lemaire, F. (1994) Comparison of three methods of gradual withdrawal from ventilatory support during weaning from mechanical ventilation. Am. J. Respir. Crit. Care Med., 150, 896-903.

De Bast, Y., De Backer, D., Moraine, J.J., Lemaire, M., Vandenborght, C. \& Vincent, J.L. (2002) The cuff leak test to predict failure of tracheal extubation for laryngeal edema. Intensive. Care Med., 28, 1267-1272.

Demling, R.H., Read, T., Lind, T.J. \& Flanagan, H.L. (1988) Incidence and morbidity of extubation failure in surgical intensive care patients. Crit. Care Med., 16, 573-577.

Efferen, L.S. \& Elsakr, A. (1998) Post-extubation stridor: risk factors and outcome. J. Assoc. Acad. Minor. Phys., 9, 65-68.

El-Solh, A., Sikka, P., Bozkanat, E., Jaafar, W. \& Davies, J. (2001) Morbid obesity in the medical ICU. Chest, 120,
1989-1997.

Engoren, M. (1999) Evaluation of the cuff-leak test in a cardiac surgery population. Chest, 116, 1029-1031.

Epstein, S.K. \& Ciubotaru, R.L. (1998) Independent effects of etiology of failure and time to reintubation on outcome for patients failing extubation. Am. J. Respir. Crit. Care Med., 158, 489-493.

Esteban, A., Alia, I., Tobin, M.J., Gil, A., Gordo, F., Vallverdu, I., Blanch, L., Bonet, A., Vazquez, A., de Pablo, R., Torres, A., de La Cal, M.A. \& Macias, S. (1999) Effect of spontaneous breathing trial duration on outcome of attempts to discontinue mechanical ventilation. Spanish Lung Failure Collaborative Group. Am. J. Respir. Crit. Care Med., 159, $512-518$.

Fisher, M.M. \& Raper, R.F. (1992) The "cuff-leak" test for extubation. Anesthesia, 47, 10-12.

Ho, L.I., Harn, H.J., Lien, T.C., Hu, P.Y. \& Wang, J.H. (1996) Postextubation laryngeal edema in adults. Risk factor evaluation and prevention by hydrocortisone. Intensive. Care Med., 22, 933-936.

Jaber, S., Chanques, G., Matecki, S., Ramonatxo, M., Vergne, C., Souche, B., Perrigault, P.F. \& Eledjam, J.J. (2003) Postextubation stridor in intensive care unit patients. Risk factors evaluation and importance of the cuff-leak test. Intensive. Care Med., 29, 69-74.

Knaus, W.A., Draper, E.A., Wagner, D.P. \& Zimmerman, J.E. (1985) APACHE II: A severity of disease classification system. Crit. Care Med., 13, 818-829.

Krieger, B.P., Ershowsky, P.F., Becker, D.A. \& Gazeroglu, H.B. (1989) Evaluation of conventional criteria for predicting successful weaning from mechanical ventilatory support in elderly patients. Crit. Care Med., 17, 858-861.

MacIntyre, N.R., Cook, D.J. \& Ely, E.W. (2001) Evidencebased guidelines for weaning and discontinuing ventilatory support Section I: Guidelines. Chest, 120, 375S-395S.

Mansharamani, N.G., Koziel, H., Garland, R., LoCicero, J., III, Critchlow, J. \& Ernst, A. (2000) Safety of bedside percutaneous dilatational tracheostomy in obese patients in the ICU. Chest, 117, 1426-1429.

Manthous, C.A., Schmidt, G.A. \& Hall, J.B. (1998) Liberation from mechanical ventilation: A decade of progress. Chest, 114, 886-901.

Marik, P.E. (1996) The cuff-leak test as a predictor of PES: a prospective study. Respir. Care., 41, 509-511.

Maury, E., Guglielminotti, J., Alzieu, M., Qureshi, T., Guidet, B. \& Offenstadt, G. (2004) How to identify patients with no risk for PES? J. Crit. Care., 19, 23-28.

Miller, R.L. \& Cole, R.P. (1996) Association between reduced cuff leak volume and PES. Chest, 110, 1035-1040.

Pierson, D.J. (2004) Invasive mechanical ventilation. In: Clinical respiratory medicine, edited by R.K. Albert, S.G. Spiro \& J.R. Jett. Philadelphia, PA, Mosby. pp. 189-209.

Raskin, M.C. \& Davis, T. (1986) Acute complications of endotracheal intubation. Chest, 89, 165-167.

Sandhu, R.S., Pasquale, M.D., Miller, K. \& Wasser, T.E. (2000) Measurement of endotracheal tube cuff leak to predict PES and need for reintubation. J. Am. Coll. Surg., 190, 682-687.

Teasdale, G. \& Jennett, B. (1974) Assessment of coma and impaired consciousness: a practical scale. Lancet, 2, 81-84.

Tobin, M.J. \& Alex, C.G. (1994) Discontinuation of mechanical ventilation. In: Principles and practice of mechanical ventilation, edited by M.J. Tobin. New York, NY: McGraw-Hill. pp. 1177-1206.

Torres, A., Gatell, J.M., Aznar, E., el-Ebiary, M., Puig de la 
Bellacasa, J., Gonzalez, J., Ferrer, M. \& Rodriguez-Roisin, R. (1995) Re-intubation increases the risk of nosocomial pneumonia in patients needing mechanical ventilation. Am. J. Respir. Crit. Care Med., 152, 137-141.

Tremblay, A. \& Bandi, V. (2003) Impact of body mass index on outcomes following critical care. Chest, 123, 1202-1207.

Tun, Y., Hida, W., Okabe, S., Ogawa, H., Kikuchi, Y., Oikawa, M., Kitamuro, T. \& Shirato, K. (2003) Can nasal continuous positive airway pressure decrease clinic blood pressure in patients with obstructive sleep apnea? Tohoku J. Exp. Med., 201, 181-190.
Voyagis, G.S., Kyriakis, K.P., Dimitrio, V. \& Vrettou, I. (1998) Value of oropharyngeal Mallampati classification in predicting difficult laryngoscopy among obese patients. Eur. J. Anaesth., 15, 330-334.

Wong, S.Y., Coskunfirat, N.S., Hee, H.I., Li, J.Y., Chen, C. \& Tseng, C.H. (2004) Factors influencing time of intubation with a lightweight device in patients without known airway abnormality. J. Clin. Anaesth., 16, 326-331.

Zweig, M.H. \& Campbell, G. (1993) Receiver-operating characteristic (ROC) plots: A fundamental evaluation tool in clinical medicine. Clin. Chem., 39, 561-577. 